\title{
Case Characteristics, Hyperacute Treatment, and Outcome Information from the Clinical Research Center for Stroke-Fifth Division Registry in South Korea
}

Beom Joon Kim, , Jong-Moo Park, ${ }^{b}$ Kyusik Kang, ${ }^{c}$ Soo Joo Lee, ${ }^{c}$ Youngchai Ko, ${ }^{c}$ Jae Guk Kim, ${ }^{c}$ Jae-Kwan Cha, ${ }^{\mathrm{d}}$ Dae-Hyun Kim, ${ }^{\mathrm{d}}$ Hyun-Wook Nah, ${ }^{\mathrm{d}}$ Moon-Ku Han, ${ }^{\mathrm{a}}$ Tai Hwan Park, ${ }^{\mathrm{e}}$ Sang-Soon Park, Kyung Bok Lee, ${ }^{\mathrm{f}}$ Jun Lee, ${ }^{\mathrm{g}}$ Keun-Sik Hong, ${ }^{\mathrm{h}}$ Yong-Jin Cho, ${ }^{\mathrm{h}}$ Byung-Chul Lee, ${ }^{\mathrm{i}}$ Kyung-Ho Yu, ${ }^{\mathrm{i}}$ Mi-Sun Oh, ${ }^{i}$ Dong-Eog Kim, ${ }^{j}$ Wi-Sun Ryu, ${ }^{j}$ Ki-Hyun Cho, ${ }^{\mathrm{k}}$ Joon-Tae Kim, ${ }^{\mathrm{k}}$ Jay Chol Choi, ${ }^{1}$ Wook-Joo Kim, ${ }^{\mathrm{m}}$ Dong-Ick Shin, ${ }^{\mathrm{n}}$ Min-Ju Yeo, ${ }^{\mathrm{n}}$ Sung Il Sohn, ${ }^{\mathrm{o}}$ Jeong-Ho Hong, ${ }^{\mathrm{o}}$ Juneyoung Lee, ${ }^{\mathrm{p}}$ Ji Sung Lee, ${ }^{\mathrm{q}}$ Byung-Woo Yoon, ${ }^{\mathrm{r}}$ Hee-Joon Bae ${ }^{\mathrm{a}}$

\footnotetext{
${ }^{a}$ Department of Neurology, Seoul National University Bundang Hospital, Seongnam, Korea

${ }^{b}$ Department of Neurology, Eulji General Hospital, Eulji University, Seoul, Korea

'Department of Neurology, Eulji University Hospital, Daejeon, Korea

${ }^{\mathrm{d}}$ Department of Neurology, Dong-A University Hospital, Busan, Korea

${ }^{e}$ Department of Neurology, Seoul Medical Center, Seoul, Korea

${ }_{\mathrm{f}}$ Department of Neurology, Soonchunhyang University Hospital Seoul, Seoul, Korea

${ }^{g}$ Department of Neurology, Yeungnam University Medical Center, Daegu, Korea

hepartment of Neurology, Inje University Ilsan Paik Hospital, Goyang, Korea

${ }^{i}$ Department of Neurology, Hallym University Sacred Heart Hospital, Anyang, Korea

'Department of Neurology, Dongguk University Ilsan Hospital, Goyang, Korea

${ }^{k}$ Department of Neurology, Chonnam National University Hospital, Gwangju, Korea

'Department of Neurology, Jeju National University Hospital, Jeju, Korea

mepartment of Neurology, Ulsan University Hospital, Ulsan, Korea

${ }^{n}$ Department of Neurology, Chungbuk National University Hospital, Cheongju, Korea

${ }^{\circ}$ Department of Neurology, Keimyung University Dongsan Medical Center, Daegu, Korea

PDepartment of Biostatistics, Korea University, Seoul, Korea

${ }^{q}$ Clinical Research Center, Asan Medical Center, Seoul, Korea

'Department of Neurology, Seoul National University Hospital, Seoul, Korea
}

Journal of Stroke 2015;17(1):38-53 http://dx.doi.org/10.5853/jos.2015.17.1.38

On page 47, the definition of stroke progression was erroneously described in the previous version of article, and the correct definition of "stroke progression" is as following;

\section{Corrected Table 5}

END event in neurologically stable patients $\geq 24$ hours

- May be attributable to peri-lesional edema

- For cases with $\leq 24$ hours after onset, END events not attributable to recurrent stroke

This is an Open Access article distributed under the terms of the Creative Commons Attribution Non-Commercial License (http://creativecommons.org/licenses/by-nc/3.0/) which permits unrestricted non-commercial use, distribution, and reproduction in any medium, provided the original work is properly cited. 
Table 5. Definitions of outcome variables in the CRCS-5 registry

\begin{tabular}{|c|c|c|}
\hline Outcome variables & Definitions & Operational definitions \\
\hline $\begin{array}{l}\text { END } \\
\text { Collected since January } 2011\end{array}$ & $\begin{array}{l}\text { Any new neurological symptoms/signs or neurological } \\
\text { worsening within } 3 \text { weeks of index stroke } \\
\text { Causes of END } \\
\text { - Recurrent stroke } \\
\text { - Stroke progression } \\
\text { - Symptomatic hemorrhagic transformation } \\
\text { - Others (deep vein thrombosis, pulmonary embolism, } \\
\text { myocardial infarction, etc.) } \\
\text { - Unknown }\end{array}$ & $\begin{array}{l}\text { Any of the following; } \\
\text { 1) Increase in total NIHSS score } \geq 2^{32} \\
\text { 2) Increase in NIHSS subscores } 1 a, 1 b \text {, or } 1 \mathrm{c} \text { (level of } \\
\text { consciousness) } \geq 1^{33} \\
\text { 3) Increase in NIHSS subscores } 5 a, 5 b \text {, 6a, or } 6 \mathrm{~b} \text { (motor) } \\
\geq 1^{32} \\
\text { 4) Any new neurological deficit (even unmeasurable by } \\
\text { NIHSS scores) }\end{array}$ \\
\hline $\begin{array}{l}\text { Recurrent stroke for END } \\
\text { (within } 3 \text { weeks of index stroke) })^{30,32}\end{array}$ & $\begin{array}{l}\text { Development of END associated with new lesions docu- } \\
\text { mented by relevant neuroimaging study }\end{array}$ & $\begin{array}{l}\text { - Discrete new lesions documented by } \\
\text { diffusion-weighted image or computed tomography } \\
\text { - If discrete, new lesions within the vascular territory of } \\
\text { the index stroke lesion may be counted } \\
\text { - Do not count for increased volume of the index stroke } \\
\text { lesions } \\
\text { - Do not count for edema, mass effect, herniation, or } \\
\text { hemorrhagic transformation of the index stroke lesions }\end{array}$ \\
\hline $\begin{array}{l}\text { Recurrent stroke } \\
\text { (late recurrence } \geq 3 \text { weeks following index stroke })^{29,31,34,36}\end{array}$ & $\begin{array}{l}\text { Rapidly developing clinical signs of focal (or global) } \\
\text { disturbance of cerebral function, with symptoms } \\
\text { lasting } 24 \text { hours or longer or leading to death, with no } \\
\text { apparent cause other than of vascular origin }{ }^{37}\end{array}$ & $\begin{array}{l}\text { Data collected through face-to-face or telephone inter- } \\
\text { view with the patient or next of kin } \\
\text { Question: Were you diagnosed with ischemic stroke or } \\
\text { hemorrhagic stroke by any doctor after discharge? }\end{array}$ \\
\hline
\end{tabular}

$\begin{array}{lc}\text { Stroke progression } & \text { END event in neurologically stable patients } \geq 24 \text { hours } \\ & \cdot \text { May be attributable to peri-lesional edema } \\ & - \text { For cases with } \leq 24 \text { hours after onset, END events not } \\ & \text { attributable to recurrent stroke } \\ & \text { END events attributable to documented hemorrhagic } \\ \text { Symptomatic hemorrhagic transformation } & \text { transformation and associated with NIHSS score } \\ & \text { increase } \geq 4 \text { points } \\ \text { Other causes of END } & \text { END events attributable to medical conditions } \\ & \text { (e.g., deep vein thrombosis, pulmonary embolization, } \\ \text { Unknown causes of END } & \text { END events not specified above }\end{array}$

Myocardial infarction

END events not specified above

For END events ( $\leq 3$ weeks after index stroke, more than two from below:

- Typical chest pain

- Troponin elevation

- ECG changes (new ST segment changes, new 0

wave, or new left bundle branch block)

For long-term outcomes ( $\geq 3$ weeks after index stroke), data collected through face-to-face or telephone interview with the patient or next of kin

- Question: Were you diagnosed with myocardial infarction by any doctors after discharge?

Vascular death

Death due to stroke, myocardial infarction, or sudden Data collected through face-to-face or telephone death ${ }^{38,39}$ interview with the patient or next of kin

- No known non-atherosclerotic cause and definite Ml or stroke within 4 weeks before death ${ }^{40}$

- No known non-atherosclerotic cause and one or both of the following: chest pain within 72 hours of death or a history of chronic ischemic heart disease (in the absence of valvular heart disease or non-ischemic cardiomyopathy ${ }^{40}$

- No known non-atherosclerotic cause and death certificate consistent with $\mathrm{CHD}$ as underlying cause $\mathrm{s}^{40}$

Non-vascular death

Death not attributable to stroke, myocardial infarction, Data collected through face-to-face or telephone or sudden death ${ }^{40}$ interview with the patient or next of kin

END, early neurological deterioration; NIHSS, National Institute of Health Stroke Scale; ECG, electrocardiography; MI, myocardial infarction; CHD, coronary heart disease. 